\title{
PERBANDINGAN HASIL BELAJAR SISWA DENGAN MODEL PEMBELAJARAN MANDIRI DAN KOOPERATIF TIPE INVESTIGASI KELOMPOK PADA SISTEM REPRODUKSI
}

\author{
Woro Tien Asrini Putri, Yulilina Retno, Refirman Dj. \\ Universitas Negeri Jakarta \\ E-maila: worotienasriniputri@yahoo.co.id
}

\begin{abstract}
Abstrak
Penelitian ini bertujuan untuk mengetahui perbedaan hasil belajar siswa dengan menggunakan model pembelajaran mandiri dan kooperatif tipe investigasi kelompok pada materi sistem Reproduksi kelas XI SMA. Metode yang digunakan adalah kuasi eksperimen. Sampel yang digunakan dalam penelitian ini sebanyak 159 siswa, 79 siswa dengan menggunakan model pembelajaran mandiri, dan 80 siswa menggunakan model pembelajaran kooperatif tipe investigasi kelompok. Penelitian ini dilaksanakan di SMAN 4 Bekasi pada semester 2 tahun ajaran 2017/2018. Analisis uji prasyarat menggunakan Kolmogorov-Smirnov untuk uji normalitas dan uji Levene's untuk homogenitas. Analisis pengujian hipotesis menggunakan uji $U$ Mann-Withney karena data tidak berdistribusi normal. Hasil uji U Mann-Withney menunjukkan bahwa terdapat perbedaan hasil belajar siswa dari kedua kelompok model pembelajaran.
\end{abstract}

Kata Kunci: bekerja sama, hasil belajar, pemecahan masalah, kepribadian

\begin{abstract}
This study aimed to determine the differences in student learning outcomes between independent learning model and cooperative learning model of group investigation on reproductive system topic for grade XI at Senior High School. The method used was quasi-experimental. The sample used in this study was 159 students, consisted of 79 students using the independent learning model, and 80 students using the cooperative learning model of group investigation. This study was conducted at SMAN 4 Bekasi in the second semester ofschool year2017/2018.Prerequisite test analysis were using Kolmogorov-Smirnov test for normality and Levene test for homogenity. Testinghypothesis analysis were using Mann-Withney $U$ test since the data was not normally distributed. The Mann-Withney $U$ test result shows that there are differences in student learning outcomes from both groups of learning models.
\end{abstract}

Keywords: cooperative, learning outcomes, problem-solving, personality

\section{PENDAHULUAN}

Pendidikan adalah suatu sistem yang terdiri dari komponen yang saling terkait untuk mencapai tujuan pendidikan. Tujuan pendidikan adalah untuk mengembangkan potensi siswa agar menjadi manusia yang beriman, bertakwa, berakhlak mulia, sehat, berilmu, kreatif, mandiri, dan bertanggung jawab. Adapun komponen-komponen dalam pendidikan antara lain adalah lingkungan, sarana-prasarana, sumberdaya, dan 
masyarakat (Munirah, 2015). Potensi siswa dapat diketahui melalui pengalaman dan penilaian belajar di sekolah. Penilaian berfungsi untuk mengetahui keberhasilan proses dan hasil belajar siswa. Proses belajar merupakankegiatanyang dilakukan oleh siswa dalam mencapai tujuan pembelajaran. Hasil belajar merupakan tingkat penguasaan yang dicapai oleh siswa dalam mengikuti program belajar mengajar, sesuai dengan tujuan yang ditetapkan. Selain itu hasil belajar adalah suatu proses untuk melihat sejauh mana siswa dapat menguasai pembelajaran setelah mengikuti kegiatan proses belajar mengajar, sedangkan penilaian hasil belajar siswa digunakan untuk mengetahui penguasaan kompetensi yang diajarkan oleh guru, kemajuan dan perkembangan hasil belajar siswa sesuai dengan potensi yang dimiliki (Sudjana, 2012).

Proses pembelajaran tidak terlepas kaitannya dengan kurikulum.Oleh karena itu,kurikulum berperan sebagai rencana pembelajaran, karena merupakansuatuprogram pendidikan yang disediakan untuk membelajarkan siswa dan sejumlah mata ajaran yang harus ditempuh kemudian dipelajari oleh siswa untuk memperoleh sejumlah pengetahuan (Syaodih, 2009).Pembelajaran dalam hal ini dapat diartikan sebagai suatu upaya menciptakan kondisi yang memungkinkan siswa dapat belajar secara efektif. Kegiatan belajar efektif terlihat dari adanya kegiatan memilih, menetapkan, danmengembangkanmetodesertamodel pembelajaran untuk mencapai tujuan pembelajaran.Guru perlu menyajikan model pembelajaran yang dapat meningkatkan minat belajar siswa, agar kompetensi dalam kegiatan pembelajaran dapat terpenuhi. Salah satu caranya dengan menggunakkan model pembelajaran yang tepat (Nyoman, Handayani, Dantes dan Suastra 2013). Model pembelajaran adalah suatu perencanaan atau pola yang digunakan sebagai pedoman dalam merencanakan pembelajaran di kelas. Model pembelajaran mengacu pada pendekatan pembelajaran yang akan digunakan, termasuk di dalamnya tujuan pengajaran, tahap-tahap dalam kegiatan pembelajaran, lingkungan pembelajaran, dan pengelolaan kelas (Chamalah, Afandi dan Wardani 2013).

Salah satu model pembelajaran yang dapat diterapakan dengan menggunakan model pembelajaran berbasis faham kontruktivisme. Pembelajaran berbasis faham kontruktivisme adalah pembelajaran yang lebih mengutamakan kepada penyelesaian masalah, pengembangan konsep. Model pembelajaran mandiri dan modelpembelajarn kooperatif termasuk ke dalam salah satu pembelajaran berbasis faham kontruktivisme (Zakaria, 2008). Model pembelajaran mandiri merupakan upaya sistematis yang dilakukan oleh siswa dalam mangatur proses pembelajarannya dalam rangka mencapai penguasaan kompetensi secara utuh. Siswa dilatih secara mandiri untuk dapat meningkatkan kemampuan dan keterampilannya sendiri dalam proses belajar agar siswa tidak bergantung pada orang lain. (Zakaria, 2008).Model pembelajaran investigasi kelompok adalah model pembelajaran kelompok dengan cara merencanakan, menemukan dan 
menyelesaikan masalah dalam bentuk diksuis kelompok sehingga tercapai tujuan pembelajaran yang telah dirumuskan bersama dengan cara melibatkan siswa dalam perencanaan baik topik yang dipelajari maupun bagaimana jalannya penyelidikan mereka(Sani, 2016).

Sistem reproduksi merupakan materi yang cukup sulit namun banyak diminati oleh siswa namun hasil belajar siswa menunjukkan nilai yang tidak terlalu baik dikarenakan menurut siswa materi sistem reproduksi adalah materi yang cukup sulit. Mengingat masalah tersebut maka pemilihan model pembelajaran sangat penting agar memudahkan siswa belajar pada saat pelajaran sistem reproduksi berlangsung. Penelitian yang dilakukan oleh Lou, Abrami dan Apollonia (2014) menunjukkan bahwa model pembelajaran small group meningkatkan hasil belajar siswa dari pada belajar secara individu dengan rata-rata pembelajaran kelompok kecil memiliki efek positif yang jauh lebih signifikan daripada pembelajaran individual terhadap prestasi individu siswa.

\section{METODE}

Metode yang digunakan dalam penelitian ini adalah metode kuasi eksperimen yaitu: tidak dapat mengontrol semua aspek yang dapat mempengaruhi pelaksaan eksperimen. Penelitian ini mempunyai 2 variabel, yaitu variabel bebas (X) model pembelajaran yang terdiri dari model pembelajaran mandiri $\left(X_{1}\right)$ dan model pembelajaran kooperatif $\left(\mathrm{X}_{2}\right)$, sedangkan variabel terikat $(\mathrm{Y})$ adalah hasil belajar siswa. Data pada penelitian ini didapatkan dengan cara memberikan tes hasil belajar untuk memperoleh data hasil pembanding dari proses pembelajaran. Tes ini dilakukan setelah pembelajaran sistem reproduksi selesai. Selain itu, data juga diperoleh dari hasil observasi keterlaksaan pembelajaran oleh guru, data berupa persentase keterlaksanaan pembelajaran pada kedua kelas eksperimen.

Populasi target dalam penelitian ini adalah seluruh siswa kelas XI yang terdapat di SMA Negeri 4 Kota Bekasi. Populasi terjangkau adalah seluruh siswa kelas XI MIPA SMA 4 Bekasi Utara pada semester genap tahun ajaran 2017/2018. Pemilihan kelas menggunakan cluster random sampling yaitu menggunakan kelas XI MIPA 1, XI MIPA 2, XI MIPA 3, dan XI MIPA 4 dengan jumlah 159 siswa.Data yang diperoleh akan diuji dan dianalisis dengan menggunakan uji statistic, melalui uji prasyarat yaitu uji normalitas dengan menggunkan uji Kolmogorov-Smirnov pada taraf signifikan $\alpha=0,05$ dan uji homogenitas menggunakan uji Lavene's pada taraf signifikan $\alpha=0,05$, selanjutnya uji statistik dengan menggunakan analisis statistik non parametrik, yaitu uji U Mann-Withney dengan taraf signifikan $\alpha=0,05$. 


\section{HASIL DAN PEMBAHASAN}

Hasil penelitian menunjukkan bahwa hasil belajar siswa dengan menggunakan model pembelajaran kooperatif tipe investigasi kelompok lebih baik dibandingkan hasil belajar siswa dengan menggunakan model pembelajaran mandiri. Hal ini dapat dilihat dari perbedaan rata-rata hasil belajar siswa kelas kooperatif tipe investigasi kelompok yang lebih tinggi dibandingkan dengan kelas mandiri. Rata-rata hasil belajar siswa yang menggunakan model pembelajaran kooperatif tipe investigasi kelompok sebesar 73.3 dan rata-rata hasil belajar siswa yang menggunakan model pembelajaran mandiri sebesar 64.8 seperti terlihat pada Gambar 1.

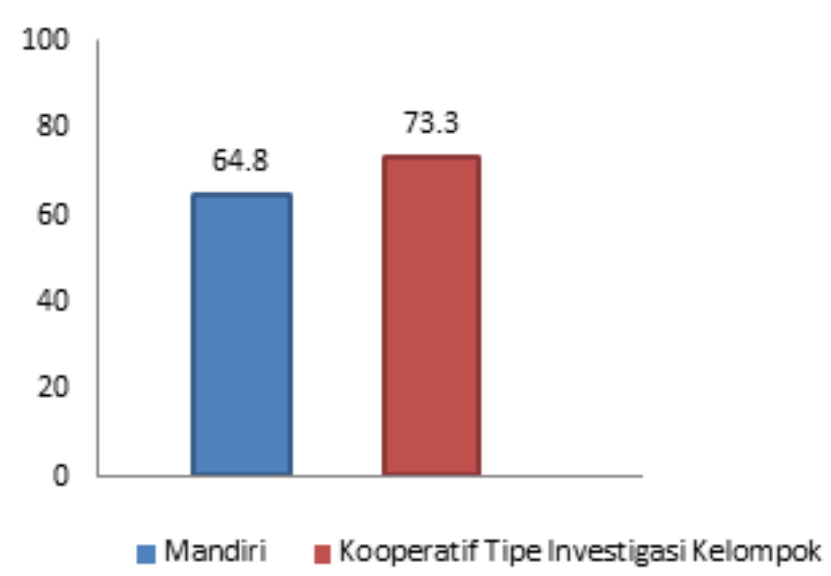

Gambar 1. Perbandingan Rata-Rata Hasil Belajar Siswa pada Kelas Mandiridan Kooperatif Tipe Investigasi Kelompok

Hasil observasi keterlaksanaan pembelajaran oleh guru menunjukkan rata-rata persentase keterlaksanaan pembelajaran kelas mandiri sebesar $97.22 \%$, sedangkan persentase keterlaksanaan pembelajaran kelas kooperatif tipe investigasi kelompok sebesar $97.365 \%$ (lihat Gambar 2).

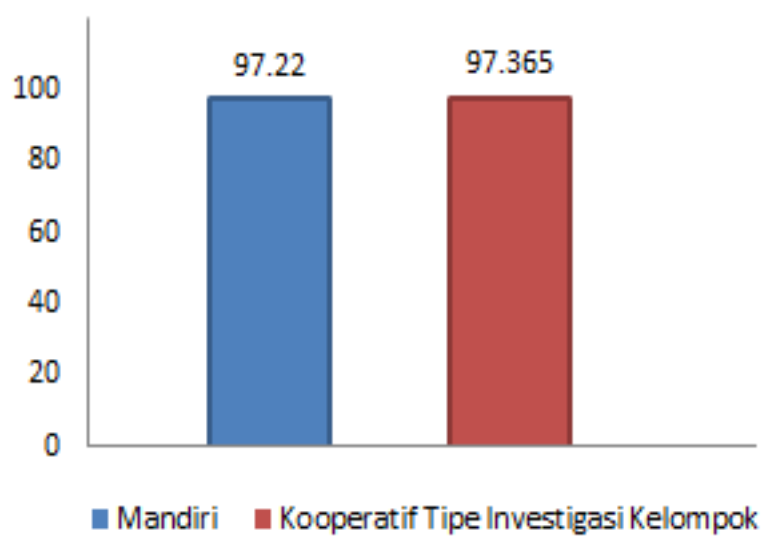

Gambar 2. Persentase Rata-Rata Hasil Observasi Keterlaksanaan Pembelajaran

Uji stastistik non parametrik dengan menggunakan uji U Mann-Withney menunjukkan adanya perbedaan hasil belajar siswa yang mengunakan model pembelajaran mandiri dan kooperatif tipe investigasi kelompok.Perbedaan hasil belajar dari kedua kelas model 
pembelajaran menunjukkan bahwa siswa lebih senang bekerja sama bersama dengan temannya, dari pada harus belajar secara mandiri. Tingginya rata-rata hasil belajar siswa dengan menggunakan model pembelajaran kooperatif tipe investigasi kelompok dikarenakan pada saat proses pembelajaran dengan model pembelajaran kooperatif tipe investigasi kelompok siswa dihadapkan pada permasalahan-permasalahan yang terkait dengan topik yang diinvestigasikan secara langsung (Sani, 2016). Hasil ini sesuai dengan penelitian Istikomah et al., (2010) bahwa pembelajaran pada kelas kooperatif tipe investigasi kelompok memberikan kesempatan kepada siswa untuk mengalami sendiri aktivitas dan pengalaman dalam belajar secara nyata. Siswa memperoleh informasi dengan mengkonstruksi sendiri data-data yang didapatkannya. Selain itu, dalam pembelajaran siswa memilih sendiri topik yang ingin mereka ivestigasi dengan cara melakukan penyelidikan, untuk memperoleh kesimpulan dari penyelidikannya dan kemudian akan dipresentasikan kepada teman-temannya.

Hasil penelitian yang telah dilakukan oleh Irwan dan Sani (2015) mendukung hasil penelitian ini bahwa kemampuan bekerjasama tim dalam model pembelajaran kooperatif akan memberikan pelajaran yang bermakna bagi siswa. Semakin baik kerja sama tim semakin baik pula proses pembelajaran berlangsung sehingga memberikan hasil belajar yang lebih baik karena, model pembelajaran kooperatif tipe investigasi kelompok sesuai dengan paham konstruktivisme yang memandang bahwa mengajar bukanlah memindahkan pengetahuan dari guru ke siswa. Tahapan-tahapan yang ada pada model pembelajaran kooperatif tipe investigasi kelompok, dapat meningkatkan kemampuan siswa dalam aspek mengkomunikasikan, menyimpulkan, dan meramalkan suatu permasalahan (Wiratana, Sadia, dan Suma 2013). Pembelajaran menggunakan model pembelajaran mandiri, memiliki rata-rata hasil belajar rendah, dikarenakan siswa diharuskan belajar mandiri dan mencari jawaban secara mandiri atas permasalahan yang ada, siswa tidak dapat berdiskusi dengan temannya untuk memecahkan masalah, sehingga siswa cukup kesulitan dalam menemukan jawaban yang tepat. Selain itu, siswa juga membutuhkan waktu yang cukup lama untuk menemukan jawaban dari permasalahannya (Nyoman et al., 2013)

Tidak semua siswa mampu membuat perencanaan belajarnya sendiri, mengimplementasikan pembelajaranya, mengevaluasi pembelajarannya, dan memenuhi kebutuhan belajarnya sendiri karena tidak memiliki kemandirian, kepercayaan diri, atau sumber belajar yang memadai, sehingga menyebabkan hasil belajar yang kurang baik (Hill, 2013).faktor-faktor yang mempengaruhi rendahnya hasil belajar siswa dalam proses pembelajaran mandiri, antara lain: (1) kesulitan dalam mengembangkan permasalahan; (2) kesulitan dalam menentukan aktivitas dan strategi belajar yang sesuai sehingga 
berdampak pada lamanya waktu pembelajaran dan (3) tidak terbiasa mengevaluasi diri terhadap kegiatan belajar yang telah dilakukan (Rachmawati, 2006).

\section{SIMPULAN}

Berdasarkan hasil pembahasan di atas dapat disimpulkan bahwa terdapat perbedaan hasil belajar siswa dengan menggunakan model pembelajaran mandiri dan kooperatif tipe investigasi kelompok pada materi sistem Reproduksi kelas XI SMA. Pembelajaran menggunakan model pembelajaran mandiri, memiliki rata-rata hasil belajar rendah, dikarenakan siswa diharuskan belajar mandiri dan mencari jawaban secara mandiri atas permasalahan yang ada, siswa tidak dapat berdiskusi dengan temannya untuk memecahkan masalah, sehingga siswa cukup kesulitan dalam menemukan jawaban yang tepat.

\section{DAFTAR PUSTAKA}

Chamalah, E., Afandi, M., \& Wardani, O. P. 2013. Model dan Metode Pembelajaran di Sekolah. Semarang: Unissula Press.

Hill, J. R. 2013. A Conceptual Model for Understanding Self-Directed Learning in Online Environments. Journal of Interactive Online Learning 6 (1), 27-42.

Irwan, N., \& Sani, R. A. 2015. Efek Model Pembelajaran Kooperatif Tipe Grouplnvestigation dan Teamwork Skills terhadap Hasil Belajar Fisika. Jurnal Pendidikan Fisika, 4 (1) 42-43.

Istikomah, H., Hendratto, S., \& Bambang, S. 2010. Penggunaan Model Pembelajaran Grouplnvestigation untuk Menumbuhkan Sikap IImiah Siswa. Jurnal Pendidikan Fisika, 6 (1), 40-43.

Lou, Y., Abrami, P. C., \& Apollonia, S. 2014. Small Group and Individual Learning with Technology: A Meta-Analysis. Review of Educational Research, 71 (3), 15-27.

Munirah. 2015. Sistem Pendidikan di Indonesia: antara keinginan dan realita. Makassar: UIN Alauddin. Sistem Pendidikan, 2 (2), 233-245.

Nyoman, N., Handayani, L., Dantes, N., \& Suastra, I. W. 2013. Pengaruh Model Pembelajaran Mandiri Terhadap Kemandirian Belajar dan Prestasi Belajar IPA Siswa Kelas VIII SMPN 3 Singaraja. e-journal Pendidikan Dasar, 3 (1) 13-14.

Rachmawati, D. O. 2006. Penerapan Model Self-Directed Learning untuk Meningkatkan Hasil Belajar dan Kemandirian. Jurnal Pendidikan dan Pengajaran , 43 (3), 177-184.

Ridwan Abdullah Sani. (2016). Inovasi Pembelajaran. Jakarta: Bumi Aksara.

Sudjana, N. (2012). Penilaian Hasil Proses Belajar Mengajar. Bandung: Remaja Rosdakarya.

Syaodih, N. (2009). Pengembangan Kurikulum. Jakarta: Remaja Rosdakarya. 
Zakaria, M. 2008. E-Learning Sebagai Model Pembelajaran Mandiri dengan Pendekatan Kooperatif dalam Rangka Meningkatkan Daya Saing Lulusan Perguruan Tinggi. JurnalPendidikan, 1 (1), 72-76. 